\title{
The relationship between electronic gaming machine accessibility and police-recorded domestic violence: $A$ spatio-temporal analysis of 654 postcodes in Victoria, Australia, 2005-2014
}

\author{
Francis Markham ${ }^{1}$, Bruce Doran ${ }^{1}$ and Martin Young ${ }^{2}$
}

Fenner School of Environment and Society, The Australian National University, Canberra, ACT, Australia ${ }^{1} \bullet$ School of Business and Tourism, Southern Cross University, Coffs Harbour, NSW, Australia ${ }^{2}$

Correspondence to: Francis Markham, Fenner School of Environment and Society, The Australian National University, Canberra, ACT, Australia. E-mail: francis.markham@anu.edu.au

This is an Accepted Manuscript of an article published by Elsevier in Social Science and Medicine on 7 June 2016, available online: http://dx.doi.org/10.1016/j. socscimed.2016.06.008

This work should be cited as:

Markham, F., Doran, B., \& Young, M. (2016). The relationship between electronic gaming machine accessibility and police-recorded domestic violence: A spatiotemporal analysis of 654 postcodes in Victoria, Australia, 2005-2014. Social Science \& Medicine, 1-9. http://doi.org/10.1016/j.socscimed.2016.06.008

\section{Abstract}

An emerging body of research has documented an association between problem gambling and domestic violence in a range of study populations and locations. Yet little research has analysed this relationship at ecological scales. This study investigates the proposition that gambling accessibility and the incidence of domestic violence might be linked.

The association between police-recorded domestic violence and electronic gaming machine accessibility is described at the postcode level. Police recorded family incidents per 10,000 and domestic-violence related physical assault offenses per 10,000 were used as outcome variables. Electronic gaming machine accessibility was measured as electronic gaming machines per 10,000 and gambling venues per 100,000. Bayesian spatio-temporal mixed-effects models were used to estimate the associations between gambling accessibility and domestic violence, using annual postcode-level data in Victoria, Australia between 2005 and 2014, adjusting for a range of covariates. 
Significant associations of policy-relevant magnitudes were found between all domestic violence and EGM accessibility variables. Postcodes with no electronic gaming machines were associated with 20\% (95\% credibility interval [C.I.]: 15\%, 24\%) fewer family incidents per 10,000 and 30\% (95\% C.I.: 24\%, 35\%) fewer domestic-violence assaults per 10,000, when compared with postcodes with 75 electronic gaming machine per 10,000. The causal relations underlying these associations are unclear. Quasi-experimental research is required to determine if reducing gambling accessibility is likely to reduce the incidence of domestic violence. 


\section{Introduction}

\section{Background and Rationale}

A multitude of studies clearly demonstrate that domestic violence is an important public health issue (see Krantz, 2002; Vine et al., 2010). Around $30 \%$ of women aged 15 or older worldwide are estimated to have been victims of intimate partner violence during their lifetime (Devries et al., 2013). In Australia, rates of domestic violence are above the global average, with $37 \%$ of women reporting ever experiencing domestic violence, and an estimated 12-month prevalence rate for intimate partner violence of $2.4 \%$ (Australian Bureau of Statistics, 2012). A substantial portion of the global burden of ill health is attributable to domestic violence (Campbell, 2002), with intimate partner violence alone estimated to account for $1 \%-2 \%$ of disability adjusted life years for women globally (Lim et al., 2012).

Despite scholarly debate about the role of gender in domestic violence, it is clear from the overwhelming weight of evidence that domestic violence is almost always perpetrated by men against women (Hamby, 2014). Cross-national evaluations of violence against women suggests that gender inequality is the most important predictor of the prevalence of such violence at the country level (Heise and Kotsadam, 2015). However, an ecological understanding of domestic violence suggests that while male dominance must be at the foundation of any theoretical account, the aetiology of domestic violence is complex and multidimensional, with many factors influencing the probability of violence operating at several geographic and conceptual levels (Heise, 1998).

An emerging body of research has examined the ecological factors that are related to the prevalence or incidence of domestic violence (Beyer et al., 2015; Pinchevsky and Wright,
2012). Disadvantage has most frequently been found to be correlated with an elevated prevalence of domestic violence, whether conceptualised as 'concentrated disadvantage' in the framework of social disorganisation theory (e.g. Gracia et al., 2015; Pinchevsky and Wright, 2012) or in terms of relative socioeconomic status (Beyer et al., 2015). Contrary to the expectations of social disorganisation theory, neither residential turnover nor neighbourhood ethnic heterogeneity have been consistently associated with the ecology of domestic violence (Pinchevsky and Wright, 2012). For both of these variables, positive, negative and null correlations have been found. Other neighbourhood-level variables found to be associated with rates of domestic violence include collective efficacy, crime, disorder, gender inequality, rurality and alcohol-outlet density, although the research field is yet to yield a consensus on the importance of many of these contextual risk factors (Beyer et al., 2015).

Gambling is an under-researched contextual factor associated with domestic violence. Although an emerging body of research suggests a strong link between domestic violence and problem gambling at the individual level, domestic violence has too often remained a "hidden" issue for those researching the health and social impacts of gambling (Korn and Shaffer, 1999). To date, the authors are aware of only one nationallyrepresentative study that has examined the association between domestic violence and problem gambling. Re-analysing the US National Comorbidity Survey Replication ( $n=3334 ; 18$ years and older), Afifi et al. (2010) found that problem gambling was associated with both intimate partner violence perpetration and victimisation. In particular, endorsing five or more DSM-IV criteria for pathological gambling was associated with elevated odds of perpetrating severe marital violence (odds ratio $[\mathrm{OR}]=20.4$ ) and severe child abuse (OR = 13.2). 
Most studies of the relationship between domestic violence and gambling have investigated convenience samples recruited in clinical contexts or among those undertaking court-mandated programs. Dowling et al. (2014) performed a meta-analysis of 14 studies examining problem gambling among victims and perpetrators of intimate partner violence and found that among problem gamblers, $38.1 \%$ report victimisation and $36.5 \%$ report perpetrating violence. The prevalence of problem gambling was estimated to be 11.3\% among perpetrators of intimate partner violence, compared with general population levels of $0.5 \%-7.6 \%$ (Williams et al., 2012). In these studies, 'problem gambling' was measured using validated screening instruments like the Problem Gambling Severity Index or used the accepted diagnostic criteria directly (Dowling et al., 2014). The balance of evidence to date suggests an association between problem gambling and intimate partner violence that persists after adjusting for factors such as poor mental health.

It is plausible that these associations reflect a causal relationship between domestic violence and gambling, a proposition that is supported by victims of violence whose partners have gambling problems (Muelleman et al., 2002; Suomi et al., 2013). For example, in one study of women aged 19-65 years presenting to an emergency department in Nebraska, 24\% of victims of intimate partner violence thought that their partner had a gambling problem. Among this subsample, $62 \%$ thought that their partners' gambling and violence were related (Muelleman et al., 2002). However victims' understanding of the causal direction of this relationship was not recorded.

Several studies suggest that gambling may increase the risk of violent incidents within families, as gambling may decrease perpetrators feelings of control over their own and their families' lives (Korman et al., 2008; Suomi et al., 2013). For example, some of the family members of problem gamblers interviewed by Suomi et al. (2013) were assaulted when their partners returned home after a gambling session, angered about lost money. Other victims of violence in the same study reported that their gambling losses triggered a violent response from their partner. Such evidence does not imply that gambling is the ultimate cause of domestic violence. Rather, gambling here may serve as an indirect mediating factor that increases the frequency and severity of aggression in violent relationships.

In the reverse causal direction, gambling may also be used as a coping mechanism by victims and perpetrators to deal with domestic violence. For example, Blaszczynski and Nower (2002) suggest that for some problem gamblers, gambling serves as a method to "modulate affective states and/or meet specific psychological needs." In other words, for some people, gambling serves as a method for blocking out negative thoughts and memories (Wood and Griffiths, 2007; Woolley and Livingstone, 2010). This mode of gambling is highly prevalent, with around $19 \%$ of Australian adults reporting that they use gambling as a method of stress management (Australian Psychological Society, 2015). We expect, therefore, a heightened gambling participation rate among both perpetrators and victims of violence as a result of violence-related stress.

Finally, it is likely that some portion of the correlation between domestic violence and problem gambling in previous studies results from shared risk factors that have not been controlled for. As such, the causal relationships between domestic violence and gambling are likely to be complex and multidirectional.

Given the documented associations between gambling and violence among individuals and their partners, it seems likely that neighbourhoods with highly accessible gambling opportunities will also have elevated rates of 
domestic violence. Gambling accessibility is of interest, as limiting venue accessibility is a policy lever that could potentially be used to reduce the incidence rate of domestic violence. Simple availability theory, borrowed from the alcohol research literature (Bruun et al., 1975; Stockwell and Gruenewald, 2003), predicts that increased gambling accessibility will increase the rate of domestic violence, via the following causal chain: (i) as gambling accessibility increases, so too does gambling participation, frequency and intensity (Pearce et al., 2008; Welte et al., 2004b; Young et al., 2012), (ii) as total gambling increases, so too does the prevalence of individuals gambling at a harmful level (Grun and McKeigue, 2000; Lund, 2008; Markham et al., 2014, 2016; Rose and Day, 1990), and (iii) as the number of people gambling more than they can afford in a population increases, so too does the incidence of domestic violence (Dowling et al., 2014). Alternatively, it is plausible that the causal chain may run in the other direction: (i) in areas with elevated rates of domestic violence, people seeking a cognitive escape will gamble more frequently and intensely than might otherwise be the case (Dowling et al., 2014) (ii) as gambling participation, frequency and intensity rise, gambling businesses become more profitable, and (iii) gambling operators will move or trade their licenses to areas with greater incidence of violence in order to profit from violence-induced demand (Marshall and Baker, 2002).

Yet few studies have examined the link between gambling accessibility and domestic violence at the ecological level. Electronic gaming machine (EGM) accessibility is of particular interest, as EGMs are most closely associated with problem gambling (MacLaren, 2015; Productivity Commission, 2010; Welte et al., 2004a) and are responsible for the largest amount of money spent by problem gamblers in Australia (Productivity Commission, 2010). In Australia, three studies have touched on this relationship al- though none have specifically analysed domestic violence rates as distinct from assault rates more generally. Barratt et al. (2014) conducted a cross-sectional spatial analysis of gambling help and violence in local government areas of Victoria. Their study did not distinguish between domestic violence and other incidents of violence, but did find that violence and access to gambling help were significantly correlated. Similarly, Wheeler et al. (2010) conducted a statistical-local area level cross-sectional spatial analysis of crime in Victoria and found significant relationships between gambling losses and the population rate of non-income generating offenses, a category which includes domestic violence assault. Finally, in a separate study of statistical-local areas in South Australia, Wheeler et al. (2008) found no relationship between gambling losses and the rate of non-income generating offenses.

In the United States, a large and controversial body of econometric literature has examined the relationship between crime and casino accessibility at various ecological scales. These studies, comprehensively reviewed by Walker (2010), have examined crime at county and city scales and have had mixed results, with some finding associations between various offenses and casino availability and others finding no significant relationship. Few of these ecologic studies specifically examined domestic violence with any degree of rigour. Other studies in the United States have been unable to disaggregate domestic violence from other violence due to their reliance on the classification of offenses imposed by the Uniform Crime Reports' standard format (e.g. Evans and Topoleski, 2002; Grinols and Mustard, 2006; Reece, 2010).

In summary, the extant literature has examined the relationship between problem gambling and domestic violence at the individual level only and in general has found significant relationships. Ecological studies of the 
impact of gambling accessibility on crime have had mixed results and have rarely focused on domestic violence specifically. This relative scholarly neglect is perhaps unsurprising, as both domestic violence (DeVerteuil, 2015) and gambling (Marshall and Baker, 2001) have been subject to relatively little geographic research.

\section{Objectives}

In this study, we examine the relationship between domestic violence and EGM accessibility at the neighbourhood level. Specifically, we undertake a spatio-temporal analysis of EGM accessibility in Victoria and annual police-recorded domestic violence between 2005 and 2014 at the postcode level. We estimate the association between the incidence of domestic violence and EGM accessibility, using two measures of EGM accessibility and two measures of policerecorded domestic violence. Because both EGM accessibility and domestic violence are correlated with variables such as socio-economic disadvantage that vary spatially and temporally, we adjust for a range of covariates that differ between postcodes.

\section{Methods}

A Bayesian spatio-temporal Poisson regression approach was used to model the relationship between domestic violence, EGM accessibility and socio-demographic covariates in Victoria, using police-recorded data aggregated by postcode and year between2005 and 2015. Bayesian spatial or spatio-temporal models are appropriate for investigating ecological correlations between variables under conditions of space-time dependence. While Bayesian methods are widely used in epidemiology, they have rarely been applied to research on domestic violence (Cunradi et al., 2011; Freisthler and Weiss, 2008; Gracia et al., 2014).

\section{Outcome variables}

We used two measures of domestic violence, both derived from the Law Enforcement Assistance Program (LEAP) database used by the Victoria Police to store police records, and provided by the Crime Statistics Agency of Victoria. The first measure was the number of 'family incidents' recorded by police in a postcode in a given calendar year. A family incident is recorded whenever domestic-violence assault, interfamilial sexual offences or child abuse are reported to police, including incidents that do not lead any charges being laid (Victoria Police, 2014). The number of family incidents recorded grew dramatically over the study period, from 28,424 in 2005 to 68,091 in 2014. The increase in recorded family incidents accelerated after 2011 when new police recording guidelines were introduced, moving from an average annual growth rate of $5.7 \%$ between 2005 and 2010 to an average of $16.4 \%$ between 2011 and 2014.

Due to the dynamism of the family incidents measure, the number of domestic violence assault offenses was used as a secondary outcome variable. Domestic violence assaults were recorded when charges were laid by police for 'assault and related offences' (classification $\mathrm{A2O}$ ) with respect to a family incident as defined above. While this category only covers some types of domestic violence acts and these for only a subset of cases, the category was selected as it was the most numerous family-incident related crime against the person. Additionally, the number of recorded family-incident related physical assaults grew less rapidly over the study period than other family-incident related offenses. Recording of domestic-violence assaults increased by $286 \%$ between 2005 and 2014, compared with a $603 \%$ growth rate in recording of all other family-incident related 
offenses. Counts of police-recorded domestic violence assaults were also aggregated to the postcode level.

Both measures of domestic violence include incidents where the perpetrators are both men and women. In 2014-15, the person identified by police as the 'primary aggressor' (Victoria Police, 2014) was a male aged 15 or more in $76 \%$ of family incidents. Women and children aged 14 or younger were the victims (or 'affected family members') in $78 \%$ of incidents.

\section{Predictor variables}

Data on the residential population of each postcode was required to calculate rates of violence. It is worth noting that while much of the American literature reviewed by Walker (2010) is concerned with adjusting for the effect of non-residents visiting in order to gamble at casinos, this issue is unlikely to have relevance in the Victorian context due to the dispersed nature of EGMs across the community. Annual estimated residential populations for Statistical Areas 2 (median 2011 population of 8562) were obtained from the Australian Bureau of Statistics for the study period (Australian Bureau of Statistics, 2015) and were converted postal areas (median population of 2831 , see Table 1 below).

The predictor variable of interest was EGM accessibility. Accessibility was measured at the postcode level in two ways: EGMs per 10,000 persons and EGM venues per 100,000 persons, each recorded separately for each postcode during each calendar year. While venue density may be considered a better measure of accessibility as it may be that distance to nearest venue is more important than venue size, EGM density is also of interest as it combines the venue density metric with an indicator of capacity. Data detailing the number of EGMs in each venue in Victoria during each year of the study period were obtained from the Victorian Commission for Gambling and Liquor Regulation. The postcode of each venue was extracted from its street address. EGM density was calculated by summing the number of EGMs in each postcode for each calendar year, and dividing that by the postcode estimated residential population.

The remaining predictor variables were derived from the Australian Census of Population and Housing, which took place in 2001, 2006 and 2011. Linear interpolation was used to provide estimates of census variable in intercensal years, while 2011 values were carried forward for the years 2012-2014.

Following calls to measure the health effects of gender (e.g. Phillips, 2011), we measured economic gender inequality by calculating the percentage of total personal income in the postcode that accrued to women. We hypothesised that domestic violence rates would be lower in areas where women had relatively more economic autonomy, as measured by the female share of personal income. We estimated the female income share using self-reported personal income data from the census, coding income brackets according to their midpoints and treating the top-coded bracket following Fleming and Measham's (2015) assumption that income is Pareto distributed.

As economic disadvantage is another key variable that is associated with both recorded domestic violence (Beyer et al., 2015; Pinchevsky and Wright, 2012) and EGM density (Marshall and Baker, 2001, 2002), the Socio-Economic Index for Areas (SEIFA) Index of Economic Resources (IER) was included as a postcode-level measure of poverty and prosperity. The IER is a composite measure of various indicators of wealth and income, which means that a more complete picture of economic status can be gained by using a single indicator, without introducing multicollinearity among 
predictor variables (Australian Bureau of Statistics, 2008).

Other included predictor variables were: the percentage of residents in the postcode who speak only English, a variable relevant to social disorganisation theory; the child-towoman ratio, selected because the number of children present in the home is an important risk factor for victimisation (Stith et al., 2004), measured as the number of children aged $0-4$ divided by the number of women aged 15-45; the percentage of the postcode who identify as Indigenous, selected due to the higher rates of victimisation among Indigenous women in Australia (Al-Yaman et al., 2006; Mouzos and Makkai, 2004); the median age of residents in the postcode, selected because domestic violence risk decreases with age (Stith et al., 2004); and the Open Accessibility and Remoteness Index for Australia (Markham, 2015), a continuous measure of the geographic accessibility of locations in Australia, selected to capture any urban-rural differences in police recording rates or domestic violence rates. The index ranges from $o$ in the most urban areas to a maximum of 15 in the most isolated parts of Australia.

During exploratory modelling, each predictor variable was tested in separate Poisson regression models, using no transformation, logarithmic transformation and a second-order polynomial transformation. The variable form that yielded the lowest DIC was retained for the main analysis.

\section{Spatial units}

Due to changes in the configuration of postcodes during the study period, four postcodes were removed from the analysis. In addition, nine postcodes were removed as they represented non-residential areas including university campuses $(n=3)$, military bases $(n=3)$, industrial zones $(n=2)$ or the central business district $(n=1)$. These areas were excluded for reasons of missing data or to reduce potential bias induced by the high ratio of visitors to residents in the central business district. This left 654 postcodes with 10 years of annual data remaining in the analysis. Postcode boundaries were approximated using the Australian Bureau of Statistic's Postal Areas.

\section{Statistical methods}

Exploratory Poisson regression modelling was undertaken assuming that data were identically and independently distributed. Variance-inflation factors (VIFs) were checked to ensure that multicollinearity was not problematic. Because the logarithmic transformations of venue density and EGM density are highly correlated $(r=0.96)$, they could not be included simultaneously in the same model, leading to the creation of separate of models. All other VIFs were in the range 1.2-3.5 (see Online Supplementary Table 1 for pairwise correlations between variables). As expected, Moran's test revealed that significant spatial autocorrelation remained in the models' residuals, while unambiguous temporal trends were also evident in model residuals. Consequently, a spatio-temporal analysis was required in order to incorporate spatial and temporal smoothing into the model.

A Bayesian Poisson mixed effects model was therefore used to estimate the association between domestic violence, EGM density and socio-demographic correlates, taking into account the spatio-temporal autocorrelation non-parametrically. A modelling approach drawing on that of Knorr-Held (2000) was adopted, as it allows for nonseparable spatial and temporal autocorrelation structures. As we were interested examining fixed estimates of parameter values rather investigating than the random effects themselves, Ugarte's et al. (2012) simplification that eliminates several nuisance para- 
meters from the Knorr-Held specification was adopted. The model used in the spatiotemporal analysis was:

$$
\begin{gathered}
\text { Incidents }_{k t} \sim \operatorname{Poisson}\left(\mu_{k t}, \text { pop }_{k t}\right) \\
\log \left(\mu_{k t}\right)=\beta X_{k t}+\log \left(\text { pop }_{k t}\right)+\phi_{t} \\
\beta \sim \mathrm{N}(0,0.001) \\
\phi_{1} \sim \mathrm{N}\left(0, \tau^{2} Q(W, \rho)^{-1}\right) \quad t=1 \\
\phi_{t} \mid \phi_{t-1} \sim \mathrm{N}\left(\gamma \phi_{t-1}, \tau^{2} Q(W, \rho)^{-1}\right) \quad t=2, \ldots, T \\
Q(W, \rho)=\rho[\operatorname{diag}(W 1)-W]+(1-\rho) I \\
\tau^{2} \sim \operatorname{Inverse} \operatorname{Gamma}(0.001,0.001) \\
\rho, \gamma \sim \operatorname{Uniform}(0,1)
\end{gathered}
$$

where the study site is divided into $k=$ $1, \ldots, K$ postcodes and $t=1, \ldots, T$ years; Incidents $_{k t}$ records the number of recorded family incidents in postcode $k$ in year $t$; pop $_{k t}$ records the population of postcode $k$ in year $t$, included as an offset term to account for variations in postcode size; $X_{k t}$ is a matrix of predictor variables in postcode $k$ in year $t$ and $\beta$ is a commensurate vector of estimated regression coefficients; $\phi_{t}$ captures spatio-temporal correlation through a set of random effects. Temporal autocorrelation is modelled through a first order autoregressive term, while spatial autocorrelation enters the model through the random effects precision matrix. The precision matrix is given by $Q(W, \rho)$ where 1 is a vector of ones and $I$ is the $K \times K$ identity matrix. The spatial adjacency matrix is given by $W . \quad \rho$ and $\gamma$ vary respectively according to the degree of spatial and temporal autocorrelation in the data, with o.o indicating no autocorrelation and 1.0 indicating strong autocorrelation.

The adjacency matrix was calculated using queen's contiguity in $\mathrm{R}$ using the spdep package (Bivand et al., 2008) with a tolerance of $10 \mathrm{~m}$. The model was fitted us- ing the CARBayesST package (Lee et al., 2015). Model parameters were estimated using Markov-Chain Monte Carlo (MCMC) simulations. A burn in period of 40,000 iterations was used, after which 200,000 samples were made. A thinning factor of five was used to reduce correlation among the simulations, meaning that parameters were effectively estimated from 40,000 simulations. Convergence was assessed by examining trace plots, with estimates of all the parameters of interest converging well.

\section{Results}

\section{Descriptive statistics}

After excluding ineligible postcodes, $4,970,000$ persons were resident in the study area in 2005 , rising to $5,800,000$ in 2014. The exclusion of ineligible postcodes removed less than $1 \%$ of the Victorian population from the analysis.

Among Victorian postcodes in 2005-2014, the median rate of family incidents and domestic-violence assaults per 10,000 were 52 and 10 respectively (see Table 1 ). However, the distribution of incidents was highly positively skewed, with the mean rate of family incidents and domestic-violence assaults much higher at 65 and 17 respectively. The distribution of EGM accessibility variables were similarly positively skewed.

Police-recorded domestic violence was highly concentrated in particular regions of Victoria (see Fig. 1). In particular, high rates of violence were recorded in the northern, western and far south-eastern suburbs of Melbourne. Similarly, EGMs are concentrated in particular regions, particularly Melbourne's western, north-western and southeastern fringes 
Table 1. Summary statistics recorded domestic violence, electronic gaming machine density and sociodemographic covariates in 654 Victorian postcodes, each year between 2005 and 2014.

Total population

Family incidents per year per 10,000

Domestic-violence assaults per year per 10,000

Venues per 100,000

EGMs per 10,000

Index of economic resources

Female income share

Per cent only speak English

Child-to-woman ratio

Per cent Indigenous

Median age

Accessibility and remoteness index for Australia

\begin{tabular}{rrrrr}
\multicolumn{1}{c}{ Mean } & \multicolumn{1}{c}{ Median } & \multicolumn{1}{c}{ SD } & \multicolumn{1}{c}{ Min } & \multicolumn{1}{c}{ Max } \\
\hline 8220.4 & 2831.3 & 11422.6 & 123.3 & 93875.6 \\
65.1 & 52.2 & 57.5 & 0.0 & 754.0 \\
16.5 & 10.3 & 23.1 & 0.0 & 475.1 \\
6.0 & 0.0 & 11.2 & 0.0 & 91.7 \\
15.5 & 0.0 & 28.7 & 0.0 & 232.5 \\
1004.1 & 999.1 & 65.0 & 811.1 & 1213.0 \\
37.8 & 37.8 & 4.7 & 13.7 & 77.8 \\
84.9 & 91.6 & 15.4 & 16.6 & 100.0 \\
0.3 & 0.3 & 0.1 & 0.0 & 1.6 \\
0.9 & 0.5 & 1.2 & 0.0 & 18.1 \\
41.1 & 40.6 & 5.8 & 20.0 & 65.0 \\
0.4 & 0.3 & 0.4 & 0.0 & 2.1 \\
\hline
\end{tabular}

2.1

Notes: Summary statistics presented in this table were not weighted by postcode population and therefore should be interpreted as representing averages among postcodes rather than the population average at state level.

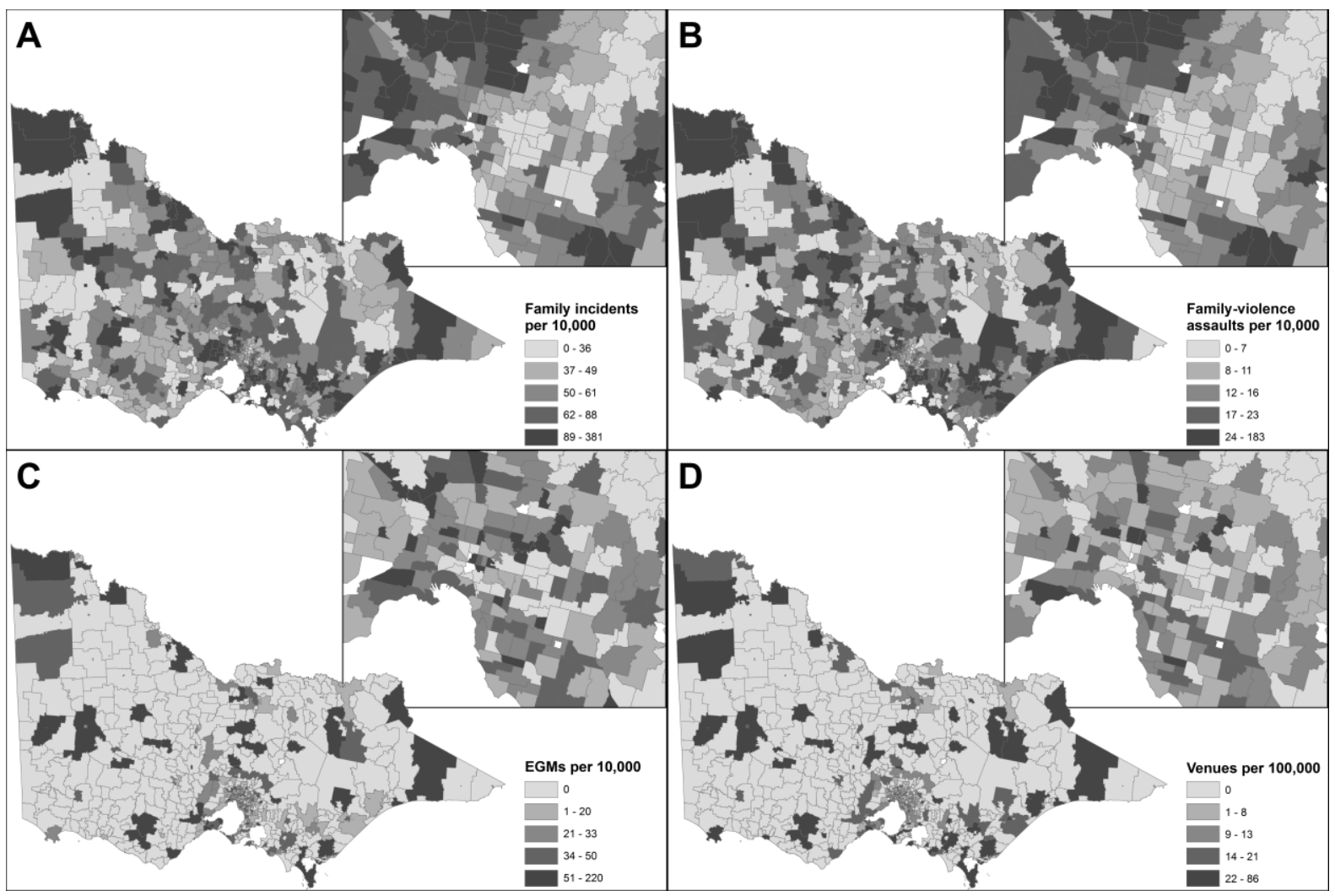

Fig. 1. Map of the unsmoothed spatial distribution of postcodes in Victoria showing (A) family incidents per 10,000; (B) family-violence assaults per 10,000; (C) EGMs per 10,000, and (D) EGM venues per 100,000. Inset maps show Greater Melbourne. All maps show the mean of annual postcode rates. 


\section{Main results}

Both venue density and EGM density were significantly associated with family incidents and domestic-violence assaults (Table 2). The model fitting process revealed the relationship to be best modelled as a logarithmic curve, indicating that the association increases rapidly with the first EGM venue in a postcode, followed by marginally smaller increases in domestic violence as accessibility increases thereafter. This correlation held both when controlling for other variables in multiple regression (Table 2) and in bivariate models (Online Supplementary Table 2).

The association between EGM density and domestic violence is presented in terms of absolute risk in Fig. 2. It is clear that while EGM accessibility is associated with violence in all four models, it explains only a small fraction of the inter-postcode variation in domestic violence rates. Table 2 shows that alternating between venues per 100,000 and EGMs per 10,000 has little substantive effect on the estimated association between EGM accessibility and domestic violence, although the DICs reported in Table 2 suggest that use of venues per 100,000 marginally improves model fit.

The index of economic resources was negatively correlated with both measures of domestic violence, meaning that there were more incidents of police-recorded violence per capita in poorer areas. Contrary to our expectations, the female income share was positively correlated with the rate of domestic violence, meaning that in postcodes where women have gained relatively more economic power, recorded violence rates are higher, not lower. The percentage of people only speaking English was negatively correlated with family incidents but was not correlated with domestic-violence assaults. The accessibility and remoteness index was negatively correlated with violence rates, meaning that police recorded a greater rate of family incidents in more urban areas.

Both $\rho$ and $\gamma$ were estimated to be relatively close to 1.0. This indicates a great degree of both spatial and temporal autocorrelation among the data. Because recording of family incidents increased during the study period much more rapidly than domestic-violence assaults, $\gamma$ is correspondingly higher for family incidents.

\section{Discussion and conclusions}

\section{Key results}

EGM density was significantly associated with both the rate of family incidents and the rate of domestic-violence assaults (Table 2). As Fig. 2 shows, EGM-free postcodes were associated with a mean incidence rate of 54 family incidents per 10,000 and 11 domesticviolence assaults per 10,000 . The mean incidence rate for postcodes with 75 EGMs per 10,000 (approximately 2 SDs above the mean), was 68 family incidents per 10,000 (95\% credibility interval [C.I.]:64, 71) and 16 domestic-violence assaults per 10,000 (95\% C.I.: 14, 17). Similar patterns were evident when venue density was used as the predictor variable. In terms of relative risk, postcodes with no EGMs were associated with $20 \%$ (95\% C.I.: $15 \%, 24 \%$ ) fewer family incidents per 10,000 and 30\% (95\% C.I.: 24\%, $35 \%)$ fewer domestic-violence assaults per 10,000, when compared with postcodes with 75 EGMs per 10,000.

Other postcode-level covariates such as economic disadvantage, female income share, the percentage of households only speaking English, the number of children per woman, the proportion of Indigenous residents and urbanicity were also found to be correlated with the increased incidence of policerecorded domestic violence. 
Table 2. Associations between domestic violence, EGM accessibility and socio-demographic characteristics from Bayesian spatio-temporal analysis

\begin{tabular}{|c|c|c|c|c|c|c|c|c|}
\hline & \multicolumn{8}{|c|}{$\beta$ coefficients } \\
\hline & \multicolumn{4}{|c|}{ Family incidents } & \multicolumn{4}{|c|}{ Domestic-violence assaults } \\
\hline & \multicolumn{2}{|c|}{ Model 1} & \multicolumn{2}{|c|}{ Model 2} & \multicolumn{2}{|c|}{ Model 3} & \multicolumn{2}{|c|}{ Model 4} \\
\hline & Est. & $95 \% \mathrm{CI}$ & Est. & $95 \% \mathrm{CI}$ & Est. & $95 \% \mathrm{CI}$ & Est. & $95 \% \mathrm{CI}$ \\
\hline $\begin{array}{l}\text { Intercept } \\
\text { In (Venues per } 100,000+1) \times 10^{1}\end{array}$ & $\begin{array}{l}-8.3 \\
0.8\end{array}$ & $\begin{array}{l}{[-9.3,-7.3]} \\
{[0.6,0.9]}\end{array}$ & -8.2 & {$[-9.2,-7.2]$} & $\begin{array}{l}-9.6 \\
0.9\end{array}$ & $\begin{array}{l}{[-11.0,-7.9]} \\
{[0.6,1.1]}\end{array}$ & -9.6 & {$[-11.1,-8.0]$} \\
\hline $\ln ($ EGMs per $10,000+1) \times 10^{1}$ & & & 0.5 & {$[0.4,0.6]$} & & & 0.8 & {$[0.6,1.1]$} \\
\hline IER $\times 10^{3}$ & -5.5 & {$[-6.0,-5.0]$} & -5.6 & {$[-6.1,-5.1]$} & -5.8 & {$[-6.6,-5.0]$} & -5.9 & {$[-6.6,-5.3]$} \\
\hline $\mathrm{IER}^{2} \times 10^{1}$ & -0.5 & {$[-4.0,2.9]$} & -0.5 & {$[-4.2,3.4]$} & 4.1 & {$[-1.3,9.2]$} & 4.2 & {$[-1.1,9.3]$} \\
\hline In Fem. income share & 0.6 & {$[0.3,0.8]$} & 0.5 & {$[0.3,0.8]$} & 0.6 & {$[0.3,0.9]$} & 0.6 & {$[0.3,0.9]$} \\
\hline In $\%$ English only $\times 10^{1}$ & 2.0 & {$[0.5,3.2]$} & 1.9 & {$[0.6,3.2]$} & 0.9 & {$[-1.0,2.7]$} & 0.9 & {$[-0.9,2.6]$} \\
\hline Child-to-woman ratio $\times 10^{1}$ & 4.7 & {$[1.3,7.7]$} & 4.4 & {$[1.6,7.6]$} & 4.9 & {$[0.5,9.4]$} & 4.7 & {$[-0.3,9.2]$} \\
\hline $\ln (\%$ Indigenous +1$) \times 10^{1}$ & 2.2 & {$[1.6,2.8]$} & 2.2 & {$[1.6,2.9]$} & 1.9 & {$[0.9,2.9]$} & 1.8 & {$[0.9,2.7]$} \\
\hline Median age $\times 10^{2}$ & -0.4 & {$[-0.9,0.4]$} & -0.4 & {$[-0.9,0.2]$} & -0.5 & {$[-1.5,0.3]$} & -0.5 & {$[-1.4,0.3]$} \\
\hline Median age $^{2}$ & 2.4 & {$[-1.8,7.5]$} & 1.4 & {$[-3.6,6.7]$} & 4.5 & {$[-2.0,12.0]$} & 4.7 & {$[-2.3,11.7]$} \\
\hline $\ln \left(\right.$ OARIA + 1) $\times 10^{1}$ & -6.6 & {$[-10.3,-3.1]$} & -7.6 & {$[-11.0,-4.9]$} & -3.4 & {$[-7.9,0.8]$} & -3.5 & {$[-7.0,0.4]$} \\
\hline$\tau^{2}$ & .11 & {$[.11, .12]$} & .12 & {$[.11, .13]$} & .23 & {$[.20, .25]$} & .23 & {$[.20, .25]$} \\
\hline$\rho$ & .95 & {$[.92, .97]$} & .95 & {$[.92, .97]$} & .97 & {$[.94, .98]$} & .97 & {$[.94, .98]$} \\
\hline$\gamma$ & .98 & {$[.96,1.00]$} & .98 & {$[.97,1.00]$} & .89 & {$[.87, .92]$} & .89 & {$[.87, .92]$} \\
\hline DIC & 39352 & & 39347 & & 2870 & & 2870 & \\
\hline
\end{tabular}

Notes: Est. = estimate; $\mathrm{CI}=$ credibility interval; $I n$ = natural logarithm; EGM = electronic gaming machine; IER = Index of economic resources; Fem. = female; OARIA = Open Accessibility and Remoteness Index; DIC = Deviance information criterion. Bold type indicates coefficients for which the $95 \%$ C.I. does not contain zero. Model coefficients are estimated simultaneously from a multivariate spatio-temporal model containing all the parameters for which coefficients were listed.
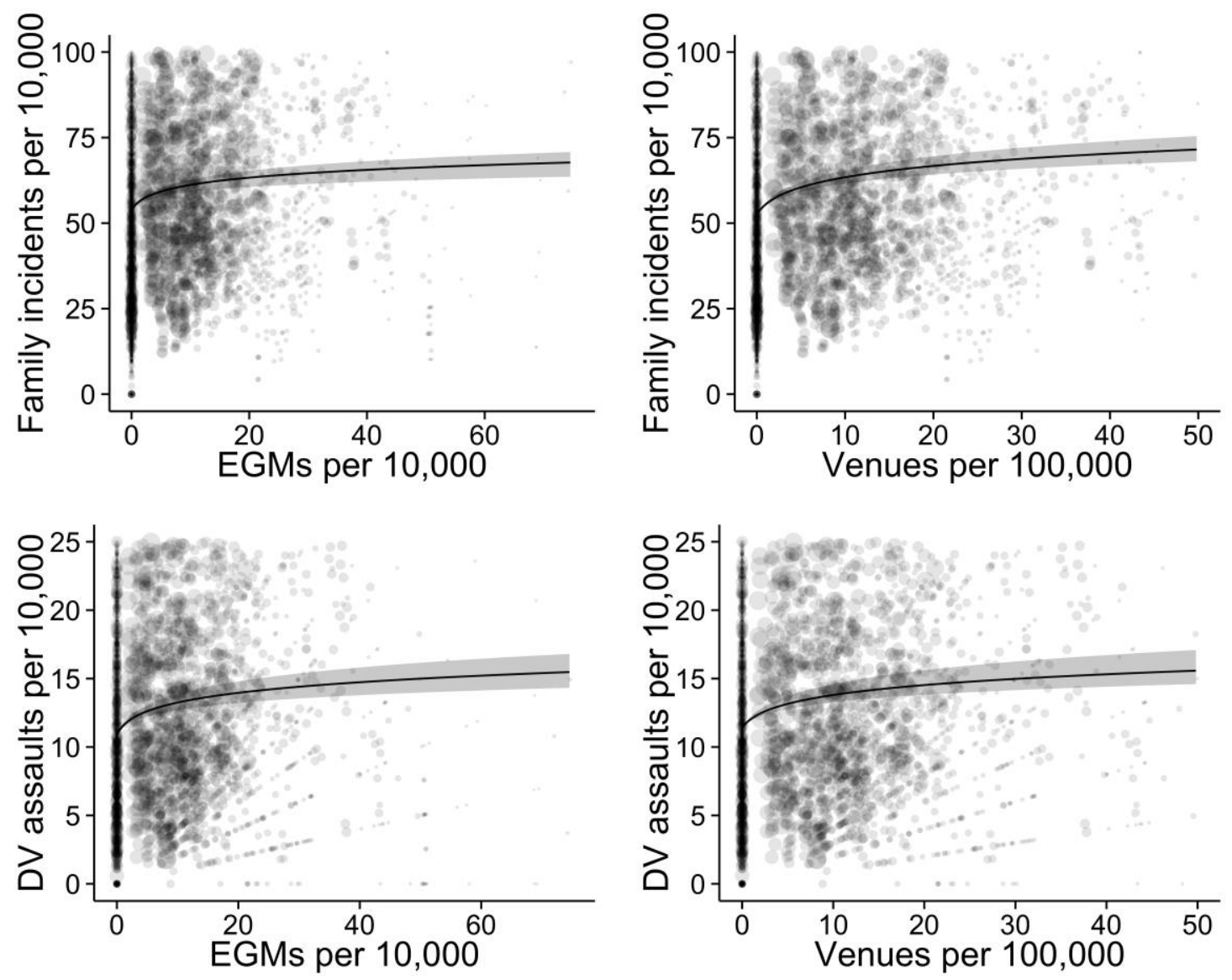

Fig. 2. Associations between domestic violence outcomes and EGM accessibility in Victoria postcodes, 20052014, after adjusting for socio-demographic characteristics from Bayesian spatial analysis. The trendline shows the estimated association between EGM accessibility and domestic violence, with the shaded grey area representing the $95 \%$ credibility interval. Each circle represents a single postcode in a single year, with the area of circles sized proportionate to the population of the postcode. 


\section{Limitations and generalisability}

These findings are subject to several limitations. First, police records routinely undercount domestic violence (Felson et al., 2002), with recorded cases sometimes likened to the tip of an "iceberg" of statistically-invisible, unrecorded cases (Gracia, 2004). This is likely to downward bias the estimated incidence of domestic violence and thus the magnitude of the estimates of absolute risk. However, our estimates of relative risk will only be biased if recording rates are spatially correlated with EGM density. We cautiously suggest that there is little $a$ priori reason to expect that this would be the case. Second, our research is subject to the modifiable areal unit problem (MAUP: Openshaw, 1984). Postcodes are not the ideal spatial units for conducting this kind of analysis. Future research could use geocoded police data to analyse the relationship between EGM accessibility and domestic violence at fine spatial scales using frame-invariant statistics (Tobler, 1990), thereby mitigating the MAUP. Analysis of geocoded police data would also enable the use of more sophisticated sub-zonal measures of EGM accessibility. Third, our estimates are associations only, limiting any causal inferences that can be made about the relationship between EGM density and domestic violence. Fourth, we did not set out to specifically investigate interactions between EGM density and other predictors of domestic violence but have instead estimated the average association between EGM density and violence across social space. Future research might investigate the potential socio-spatial nonstationarity of these relationships.

We see little prima facie reason to doubt that our results are generalizable to other jurisdictions in high income countries where EGMs are accessible throughout the community. While the incidence rates are highly dependent on police recording protocols, we expect that the underlying relationship will be present in other jurisdictions.

\section{Interpretation}

There is an association between EGM density and domestic violence rates among postcodes, above and beyond that explained by the geography of contextual factors like disadvantage. That is to say, once the effect of disadvantage and other covariates are controlled for, a correlation between EGM density and violence remains. The logarithmic shape of the relationship suggests that the first few EGM venues added to an area have the greatest impact on domestic violence rates.

Gambling is likely to be both a cause and effect of domestic violence. Furthermore, despite our efforts to find neighbourhood-level proxies for domestic violence risk factors, it is likely that the correlation between EGM accessibility and domestic violence results partly from the correlation of both these variables with other unobserved variables like alcohol-outlet density. We expect that all three of these causal pathways contribute to some extent to the association we have documented, although their relative importance is unclear.

The magnitude of these estimated associations is larger than we anticipated and suggests that the relationship between EGM accessibility and domestic violence is policy relevant. If all of this association results from gambling-caused domestic violence (rather than the other two causal pathways mentioned above), we would expect that reducing the accessibility of EGMs or removing them entirely would result in a substantially reduced incidence of domestic violence. A more plausible interpretation is that only a fraction of the estimated association is 
attributable to gambling-caused domestic violence. Further study using strong quasi-experimental designs is needed to disentangle the multiple causal pathways to this association and to estimate the magnitude of potential reductions in the domestic violence incidence rate that may occur if EGM accessibility were decreased.

As Fig. 2 demonstrates, EGM accessibility only explains a small portion of the variation in the rate of police-recorded domestic violence between postcodes. This implies that reducing EGM density is unlikely to be a policy priority for those seeking to reduce rates of domestic violence. However, domestic violence should be considered as a relevant social impact by authorities licensing EGMs.

Consistent with the broader literature and social disorganisation theory, economically disadvantaged postcodes have an elevated rate of police-recorded domestic violence (Beyer et al., 2015; Pinchevsky and Wright, 2012), although it is possible that this correlation is due to more intensive policing of poorer areas. Our finding that postcodes with greater linguistic diversity experience lower rates of police-recorded domestic violence is contrary to the expectations of social disorganisation theory, but consistent with non-ecological surveys in Australia (Mouzos and Makkai, 2004; O'Donnell et al., 2002). Contrary to our expectations, postcodes with a greater female income share also had elevated rates of violence. Jewkes (2002), writing about similar relationships between intimate partner violence and female education in the United States and South Africa, suggests that as women gain more power they pose a greater challenge to patriarchal authority, a challenge that may be met with violence. Finally, the finding that policerecorded violence rates are higher in urban areas when urbanicity is measured using a continuous measure of remoteness and accessibility is novel in the research literature, which has rarely measured the urban-rural continuum using non-binary measures in developed countries (Beyer et al., 2015).

\section{Conclusions}

EGM accessibility is associated with policerecorded domestic violence incidence in postcodes in Victoria. Reducing EGM accessibility may potentially provide an avenue for reducing the incidence of domestic violence. Further research utilising strong quasi-experimental designs should be undertaken to disentangle the causal relations underlying this association. 


\section{Disclosure of competing interests}

All authors have received funding from or been employed on projects funded by the Australian Research Council; the Community Benefit Fund (Northern Territory Government); and the Northern Territory Research and Innovation Fund (Northern Territory Government). M.Y. has received funding from the Department of Justice (Victorian Government) and Gambling Research Australia. B.D. has received funding from the Research and Community Engagement Division (Queensland Government) and the Department of Justice (Victorian Government). F.M. holds an Australian Postgraduate Award and has been employed on research projects funded by the Australian Capital Territory Gambling and Racing Commission. F.M. and M.Y. are members of the National Association for Gambling Studies (Australia). F.M. is a member of the Public Health Association of Australia.

\section{Funding}

F.M. was supported by an Australian Postgraduate Award from the Department of Education, Australia. The funding body did not commission this research or have any role in its design, execution or publication. No constraints were placed on the publication of this manuscript.

\section{Acknowledgements}

We thank the Crime Statistics Agency of Victoria and the Victorian Commission for Gambling and Liquor Regulation for providing the data used in this study.

\section{Appendix A. Supplementary data}

Supplementary data related to this article can be found at http://dx.doi.org/10.1016/j. socscimed.2016.06.008.

\section{References}

Afifi, T. O., Brownridge, D. A., MacMillan, H., \& Sareen, J. (2010). The relationship of gambling to intimate partner violence and child maltreatment in a nationally representative sample. Journal of Psychiatric Research, 44(5), 331-337. http://doi.org/10.1016/j.jpsychires.2009.07.010

Al-Yaman, F., Van Doeland, M., \& Wallis, M. (2006). Family violence among Aboriginal and Torres Strait Islander peoples (Catalogue No. IHW 17). Canberra: Australian Institute of Health and Welfare. Retrieved from http://www.aihw.gov.au/publication-detail/?id=6442467912 archived at http://www.webcitation.org/6d6BytMUn 
Australian Bureau of Statistics. (2008). An Introduction to Socio-Economic Indexes for Areas (SEIFA), 2006 (No. 2039.0). Canberra: Australian Bureau of Statistics. Retrieved from http://www.abs.gov.au/ausstats/abs@.nsf/mf/2039.o/ archived at http://www.webcitation.org/67tGG7kJi

Australian Bureau of Statistics. (2012). Personal Safety Survey (2012) (Expanded CURF, RADL. Findings based on use of ABS CURF data.).

Australian Bureau of Statistics. (2015). Regional Population Growth, Australia, 2013-14 (Catalogue No. 3218.o). Canberra: Australian Bureau of Statistics. Retrieved from http://www.abs.gov.au/AUSSTATS/abs@.nsf/DetailsPage/3218.0201314?OpenDocument

Australian Psychological Society. (2015). Stress and wellbeing: How Australians are coping with life. Melbourne. Retrieved from http://www.psychology.org.au/Assets/Files/PW15-SR.pdf archived at http://www.webcitation.org/6d4TELRHo

Barratt, M. J., Livingston, M., Matthews, S., \& Clemens, S. L. (2014). Gaming machine density is correlated with rates of help-seeking for problem gambling: a local area analysis in Victoria, Australia. Journal of Gambling Issues, 1-21. http://doi.org/10.4309/jgi.2014.29.1

Beyer, K., Wallis, A. B., \& Hamberger, L. K. (2015). Neighborhood Environment and Intimate Partner Violence A Systematic Review. Trauma, Violence, \& Abuse, 16(1), 16-47. http://doi.org/10.1177/1524838013515758

Bivand, R. S., Pebesma, E. J., \& Gómez-Rubio, V. (2008). Applied Spatial Data Analysis with $R$. New York: Springer.

Blaszczynski, A., \& Nower, L. (2002). A pathways model of problem and pathological gambling. Addiction, 97(5), 487-499. http://doi.org/10.1046/j.13600443.2002.00015.x

Bruun, K., Edwards, G., Lumio, M., Mäkelä, K., Pan, L., Popham, R., ... Österberg, E. (1975). Alcohol control policies in public health perspective. Helsinki: The Finnish Foundation for Alcohol Studies.

Campbell, J. C. (2002). Health consequences of intimate partner violence. The Lancet, 359(9314), 1331-1336. http://doi.org/10.1016/So140-6736(02)o8336-8

Cunradi, C. B., Mair, C., Ponicki, W., \& Remer, L. (2011). Alcohol Outlets, Neighborhood Characteristics, and Intimate Partner Violence: Ecological Analysis of a California City. Journal of Urban Health, 88(2), 191-200. http://doi.org/10.1007/s11524-0119549-6

DeVerteuil, G. (2015). Conceptualizing violence for health and medical geography. Social Science \& Medicine, 133, 216-222. http://doi.org/10.1016/j.socscimed.2015.01.018 
Devries, K. M., Mak, J. Y. T., García-Moreno, C., Petzold, M., Child, J. C., Falder, G., ... Watts, C. H. (2013). The Global Prevalence of Intimate Partner Violence Against Women. Science, 340(6140), 1527-1528. http://doi.org/10.1126/science.1240937

Dowling, N., Suomi, A., Jackson, A., Lavis, T., Patford, J., Cockman, S., ... Abbott, M. (2014). Problem Gambling and Intimate Partner Violence A Systematic Review and MetaAnalysis. Trauma, Violence, \& Abuse, 1524838014561269. http://doi.org/10.1177/1524838014561269

Evans, W. N., \& Topoleski, J. H. (2002). The Social and Economic Impact of Native American Casinos (Working Paper No. 9198). National Bureau of Economic Research. Retrieved from http://www.nber.org/papers/w9198

Felson, R. B., Messner, S. F., Hoskin, A. W., \& Deane, G. (2002). Reasons for Reporting and Not Reporting Domestic Violence to the Police. Criminology, 4O(3), 617-648. http://doi.org/10.1111/j.1745-9125.2002.tboo968.x

Fleming, D. A., \& Measham, T. G. (2015). Income Inequality across Australian Regions during the Mining Boom: 2001-11. Australian Geographer, 46(2), 203-216. http://doi.org/10.1080/00049182.2015.1020596

Freisthler, B., \& Weiss, R. E. (2008). Using Bayesian Space-Time Models to Understand the Substance Use Environment and Risk for Being Referred to Child Protective Services. Substance Use \& Misuse, 43(2), 239-251. http://doi.org/10.1080/10826080701690649

Gracia, E. (2004). Unreported cases of domestic violence against women: towards an epidemiology of social silence, tolerance, and inhibition. Journal of Epidemiology and Community Health, 58(7), 536-537. http://doi.org/10.1136/jech.2003.019604

Gracia, E., López-Quílez, A., Marco, M., Lladosa, S., \& Lila, M. (2014). Exploring Neighborhood Influences on Small-Area Variations in Intimate Partner Violence Risk: A Bayesian Random-Effects Modeling Approach. International Journal of Environmental Research and Public Health, 11(1), 866-882. http://doi.org/10.3390/ijerph110100866

Gracia, E., López-Quílez, A., Marco, M., Lladosa, S., \& Lila, M. (2015). The Spatial Epidemiology of Intimate Partner Violence: Do Neighborhoods Matter? American Journal of Epidemiology, 182(1), 58-66. http://doi.org/10.1093/aje/kwvo16

Grinols, E. L., \& Mustard, D. B. (2006). Casinos, Crime, and Community Costs. Review of Economics and Statistics, 88(1), 28-45. http://doi.org/10.1162/rest.2006.88.1.28

Grun, L., \& McKeigue, P. (2000). Prevalence of excessive gambling before and after introduction of a national lottery in the United Kingdom: another example of the single distribution theory. Addiction, 95(6), 959-966. http://doi.org/10.1046/j.13600443.2000.95695912.x 
Hamby, S. (2014). Intimate Partner and Sexual Violence Research Scientific Progress, Scientific Challenges, and Gender. Trauma, Violence, \& Abuse, 15(3), 149-158. http://doi.org/10.1177/1524838014520723

Heise, L. L. (1998). Violence Against Women An Integrated, Ecological Framework. Violence Against Women, 4(3), 262-290. http://doi.org/10.1177/1077801298004003002

Heise, L. L., \& Kotsadam, A. (2015). Cross-national and multilevel correlates of partner violence: an analysis of data from population-based surveys. The Lancet Global Health, 3(6), e332-e340. http://doi.org/10.1016/S2214-109X(15)ooo13-3

Jewkes, R. (2002). Intimate partner violence: causes and prevention. The Lancet, 359(9315), 1423-1429. http://doi.org/10.1016/So140-6736(o2)o8357-5

Knorr-Held, L. (2000). Bayesian modelling of inseparable space-time variation in disease risk. Statistics in Medicine, 19(17-18), 2555-2567. http://doi.org/10.1002/1097o258(20000915/30)19:17/18<2555::AID-SIM587>3.0.CO;2-\#

Korman, L. M., Collins, J., Dutton, D., Dhayananthan, B., Littman-Sharp, N., \& Skinner, W. (2008). Problem Gambling and Intimate Partner Violence. Journal of Gambling Studies, 24(1), 13-23. http://doi.org/10.1007/s10899-007-9077-1

Korn, D. A., \& Shaffer, H. J. (1999). Gambling and the Health of the Public: Adopting a Public Health Perspective. Journal of Gambling Studies, 15(4), 289-365. http://doi.org/10.1023/A:1023005115932

Krantz, G. (2002). Violence against women: a global public health issue! Journal of Epidemiology and Community Health, 56(4), 242-243. http://doi.org/10.1136/jech.56.4.242

Lee, D., Rushworth, A., \& Napier, G. (2015). CARBayesST: An R Package for Spatiotemporal Areal Unit Modelling with Conditional Autoregressive Priors (pp. 1-12).

Lim, S. S., Vos, T., Flaxman, A. D., Danaei, G., Shibuya, K., Adair-Rohani, H., ... Ezzati, M. (2012). A comparative risk assessment of burden of disease and injury attributable to 67 risk factors and risk factor clusters in 21 regions, 1990-2010: a systematic analysis for the Global Burden of Disease Study 2010. The Lancet, 380(9859), 2224-2260. http://doi.org/10.1016/So140-6736(12)61766-8

Lund, I. (2008). The Population Mean and the Proportion of Frequent Gamblers: Is the Theory of Total Consumption Valid for Gambling? Journal of Gambling Studies, 24(2), 247-256. http://doi.org/10.1007/s10899-007-9081-5

MacLaren, V. V. (2015). Video Lottery is the Most Harmful Form of Gambling in Canada. Journal of Gambling Studies, 1-27. http://doi.org/10.1007/s10899-015-9560-z

Markham, F., Young, M., \& Doran, B. (2014). Gambling expenditure predicts harm: evidence from a venue-level study. Addiction, 109(9), 1509-1516.

http://doi.org/10.1111/add.12595 
Markham, F., Young, M., \& Doran, B. (2016). The relationship between player losses and gambling-related harm: evidence from nationally representative cross-sectional surveys in four countries. Addiction, 111(2), 320-330. http://doi.org/10.1111/add.13178

Marshall, D., \& Baker, R. G. V. (2001). Clubs, Spades, Diamonds and Disadvantage: the Geography of Electronic Gaming Machines in Melbourne. Australian Geographical Studies, 39(1), 17-33. http://doi.org/10.1111/1467-8470.00127

Marshall, D., \& Baker, R. G. V. (2002). The Evolving Market Structures of Gambling: Case Studies Modelling the Socioeconomic Assignment of Gaming Machines in Melbourne and Sydney, Australia. Journal of Gambling Studies, 18(3), 273-291. http://doi.org/10.1023/A:1016847305942

Mouzos, J., \& Makkai, T. (2004). Women's experiences of male violence: Findings form the Australian Component of the International Violence Against Women Survey (IVAWS) (Research and Public Policy Series No. 56). Canberra: Australian Institute of Criminology.

Muelleman, R. L., Den Otter, T., Wadman, M. C., Tran, T. P., \& Anderson, J. (2002). Problem gambling in the partner of the emergency department patient as a risk factor for intimate partner violence. The Journal of Emergency Medicine, 23(3), 307-312. http://doi.org/10.1016/So736-4679(02)00543-7

O’Donnell, C. J., Smith, A., \& Madison, J. R. (2002). Using Demographic Risk Factors to Explain Variations in the Incidence of Violence Against Women. Journal of Interpersonal Violence, 17(12), 1239-1262. http://doi.org/10.1177/o88626002237854

Openshaw, S. (1984). The Modifiable Areal Unit Problem (CATMOG No. 38). Norwich: Geo Books.

Pearce, J., Mason, K., Hiscock, R., \& Day, P. (2008). A national study of neighborhood access to gambling opportunities and individual gambling behaviour. Journal of Epidemiology and Community Health, 62, 862-868. http://doi.org/10.1136/jech. 2007.068114

Phillips, S. P. (2011). Including Gender in Public Health Research. Public Health Reports (1974-), 126, 16-21.

Pinchevsky, G. M., \& Wright, E. M. (2012). The Impact of Neighborhoods on Intimate Partner Violence and Victimization. Trauma, Violence, \& Abuse, 13(2), 112-132. http://doi.org/10.1177/1524838012445641

Productivity Commission. (2010). Gambling (Report No. 50). Canberra: Productivity Commission.

Reece, W. S. (2010). Casinos, Hotels, and Crime. Contemporary Economic Policy, 28(2), 145-161. http://doi.org/10.1111/j.1465-7287.2009.00172.x 
Rose, G., \& Day, S. (1990). The Population Mean Predicts The Number Of Deviant Individuals. BMJ: British Medical Journal, 301(6759), 1031-1034.

Stith, S. M., Smith, D. B., Penn, C. E., Ward, D. B., \& Tritt, D. (2004). Intimate partner physical abuse perpetration and victimization risk factors: A meta-analytic review. Aggression and Violent Behavior, 10(1), 65-98. http://doi.org/10.1016/j.avb.2003.09.001

Stockwell, T., \& Gruenewald, P. J. (2003). Controls on the Physical Availability of Alcohol. In T. Stockwell \& N. Heather (Eds.), The essential handbook of treatment and prevention of alcohol problems (pp. 213-233). New York: Wiley, J. Wiley.

Suomi, A., Jackson, A. C., Dowling, N. A., Lavis, T., Patford, J., Thomas, S. A., ... Cockman, S. (2013). Problem gambling and family violence: family member reports of prevalence, family impacts and family coping. Asian Journal of Gambling Issues and Public Health, 3(1), 1-15.

Tobler, W. R. (1990). Frame independent spatial analysis. In M. Goodchild \& S. Gopal (Eds.), Accuracy of spatial databases (pp. 115-122). London: Taylor \& Francis.

Ugarte, M. D., Etxeberria, J., Goicoa, T., \& Ardanaz, E. (2012). Gender-specific spatiotemporal patterns of colorectal cancer incidence in Navarre, Spain (1990-2005). Cancer Epidemiology, 36(3), 254-262. http://doi.org/10.1016/j.canep.2011.10.004

Victoria Police. (2014). Code of Practice for the Investigation of Family Violence: Edition 3 V2 2014. Melbourne. Retrieved from https://www.police.vic.gov.au/retrievemedia.asp?Media_ID=464 archived at http://www.webcitation.org/6XZyUwgbT

Vine, M. M., Elliott, S. J., \& Keller-Olaman, S. (2010). To disrupt and displace: placing domestic violence on the public health agenda. Critical Public Health, 2O(3), 339355. http://doi.org/10.1080/09581590903419586

Walker, D. M. (2010). Casinos and crime in the USA. In B. L. Benson \& P. R. Zimmerman (Eds.), Handbook on the economics of crime (pp. 488-517). Northampton, MA: Edward Elgar.

Welte, J. W., Barnes, G. M., Wieczorek, W. F., Tidwell, M.-C. O., \& Parker, J. C. (2004). Risk factors for pathological gambling. Addictive Behaviors, 29(2), 323-335. http://doi.org/10.1016/j.addbeh.2003.08.007

Welte, J. W., Wieczorek, W. F., Barnes, G. M., Tidwell, M.-C. O., \& Hoffman, J. H. (2004). The relationship of ecological and geographic factors to gambling behavior and pathology. Journal of Gambling Studies, 2O(4), 405-423. http://doi.org/10.1007/s10899-004-4582-y

Wheeler, S. A., Round, D. K., Sarre, R., \& O’Neil, M. (2008). The influence of gaming expenditure on crime rates in South Australia: A local area empirical investigation. Journal of Gambling Studies, 24(1), 1-12. 
Wheeler, S. A., Round, D. K., \& Wilson, J. K. (2010). The Relationship Between Crime and Electronic Gaming Expenditure: Evidence from Victoria, Australia. Journal of Quantitative Criminology, 27(3), 315-338. http://doi.org/10.1007/s10940-0109123-5

Williams, R. J., Volberg, R. A., \& Stevens, R. M. G. (2012). The population prevalence of problem gambling: methodological influences, standardized rates, jurisdictional differences, and worldwide trends (Technical Report). Ontario Problem Gambling Research Centre. Retrieved from http://www.uleth.ca/dspace/handle/10133/3068 archived at http://www.webcitation.org/6OK7CeYsW

Wood, R. T. A., \& Griffiths, M. D. (2007). A qualitative investigation of problem gambling as an escape-based coping strategy. Psychology and Psychotherapy: Theory, Research and Practice, 8o(1), 107-125. http://doi.org/10.1348/147608306X107881

Woolley, R., \& Livingstone, C. (2010). Into the zone: innovating in the Australian poker machine industry. In S. Kingma (Ed.), Global Gambling-Cultural Perspectives on Gambling Organizations (pp. 38-63). London; New York: Routledge.

Young, M., Markham, F., \& Doran, B. (2012). Too close to home? The relationships between residential distance to venue and gambling outcomes. International Gambling Studies, 12(2), 257-273. http://doi.org/10.1080/14459795.2012.664159 